\title{
BMJ Open Prevalence of overweight and obesity and some associated factors among adult residents of northeast China: a cross-sectional study
}

\author{
Rui Wang, Peng Zhang, Chunshi Gao, Zhijun Li, Xin Lv, Yuanyuan Song, \\ Yaqin $\mathrm{Yu}$, Bo Li
}

To cite: Wang $R$, Zhang $P$, Gao $\mathrm{C}$, et al. Prevalence of overweight and obesity and some associated factors among adult residents of northeast China: a crosssectional study. BMJ Open 2016;6:e010828. doi:10.1136/bmjopen-2015010828

- Prepublication history for this paper is available online. To view these files please visit the journal online (http://dx.doi.org/10.1136/ bmjopen-2015-010828).

Received 10 December 2015 Revised 29 March 2016 Accepted 13 April 2016

CrossMark

Department of Epidemiology and Biostatistics, Jilin University School of Public Health, Changchun, Jilin, China

Correspondence to

Professor Bo Li;

li_bo@jlu.edu.cn

\section{ABSTRACT}

Objectives: This study aims to estimate the prevalence of overweight and obesity and determine potential influencing factors among adults in northeast China.

Methods: A cross-sectional survey was conducted in Jilin Province, northeast China, in 2012. A total of 9873 men and 10966 women aged 18-79 years from the general population were included using a multistage stratified random cluster sampling design. Data were obtained from face-to-face interview and physical examination. After being weighted according to a complex sampling scheme, the sample was used to estimate the prevalence of overweight (body mass index (BMI) $24-27.9 \mathrm{~kg} / \mathrm{m}^{2}$ ) and obesity (BMI >28 kg/ $\mathrm{m}^{2}$ ) in Jilin Province, and analyse influencing factors through corresponding statistical methods based on complex sampling design behaviours.

Results: The overall prevalence of overweight was $32.3 \%$ (male $34.3 \%$; female $30.2 \%$ ), and the prevalence of obesity was $14.6 \%$ (male $16.3 \%$; female $12.8 \%$ ) in Jilin Province. The prevalence of both overweight and obesity were higher in men than women $(p<0.001)$. Influencing factors included sex, age, marriage status, occupation, smoking, drinking, diet and hours of sleep $(p<0.05)$.

Conclusions: This study estimated that the prevalence of overweight and obesity among adult residents of Jilin Province, northeast China, were high. The results of this study will be submitted to the Health Department of Jilin Province and other relevant departments as a reference, which should inform policy makers in developing education and publicity to prevent and control the occurrence of overweight and obesity.

\section{INTRODUCTION}

Overweight and obesity have been shown to be related to multiple chronic conditions, and lead to a heavy economic burden on families and increasing costs to society throughout the world. ${ }^{1-3}$ According to a

\section{Strengths and limitations of this study}

- The main strengths of this study are its large sample size and precise physical measurement, which improved the validity of the results.

- Some potential limitations existed in this crosssectional study. Self-reported data and the nature of cross-sectional data may lead to recall and reporting biases, which may have affected the accuracy of the results.

- The results were from Jilin Province only and therefore cannot be generalised to the whole northeast of China.

WHO report, ${ }^{4}$ obesity is defined as a body mass index (BMI) $\geq 30 \mathrm{~kg} / \mathrm{m}^{2}$, and overweight as a BMI of 25-29.9 $\mathrm{kg} / \mathrm{m}^{2}$. For Chinese people, obesity suggests a BMI $\geq 28 \mathrm{~kg} / \mathrm{m}^{2}$ and overweight indicates a BMI of 24-27.9 kg/m ${ }^{25}$ In 2013, in order to make physicians pay more attention to the condition, the American Medical Association classified obesity as a disease. ${ }^{6}$

China is the largest developing country and has the largest population in the world. Its rapid economic growth and enviable developmental performance have contributed to changes in lifestyle such as dietary habits and physical activity. ${ }^{7}$ Over the past few decades, China has witnessed an obesity epidemic which has led to various diseases, especially chronic ones. Overweight and obesity have become a major public health problem in China, although the prevalence of obesity is lower than in developed countries. ${ }^{4}{ }^{8} 9$ Previous research suggests that there has been a significant increase in the prevalence of obesity in the USA and Canada over the past few years, ${ }^{10}$ and the same scenario as has played out in China recently, and there is no doubt that the rapidly increasing occurrence of overweight 
and obesity in China will continue to increase the prevalence of chronic diseases. ${ }^{11-13}$ Therefore, understanding influencing factors associated with overweight and obesity will be useful for policy makers in formulating policies to diminish the rate and to control related comorbid conditions.

Jilin Province is located in northeast China, and has a large population of about 27 million. ${ }^{14}$ In 2012, Jilin Department of Health and Jilin University jointly conducted the Jilin Provincial Chronic Disease Survey, which is the first large representative population-based survey of chronic disease in this area. Data used in our study were obtained from this survey. In this article, we estimate the prevalence of overweight/obesity and explore potential influencing factors in adult residents of northeast China. The result of this study will be considered as a reference for policy makers in making informed decisions.

\section{METHODS}

\section{Study design and population}

This population-based cross-sectional survey is part of the Project on Present Situation and Change Forecast of Disease Spectrum in Jilin Province of China in 2012. Face-to-face interviews on health and physical examinations were performed for the Jilin Provincial Chronic Disease Survey in residents aged 18-79 years; all the subjects included had lived in Jilin Province for more than 6 months. The sample size calculation of this survey was used to estimate the prevalence of overweight and obesity in Jilin Province. The ultimate target sample size was established to be 25240 , accounting for about $1 \%$ o of the total adult population of Jilin Province.

We used the multistage stratified cluster sampling method to select the study sample. First, we stratified Jilin Province into nine regions (Changchun, Jilin (city), Siping, Liaoyuan, Tonghua, Baishan, Songyuan, Baicheng and Yanbian) covering the whole of Jilin. These regions are all primarily responsible for the administration of healthcare services. Then, from each of the nine regions, we randomly selected clusters of four districts or counties. Thirty-two districts or counties, 95 towns or communities, and 45 units were selected. Finally, each participant was selected randomly from each household in the sites mentioned above. ${ }^{1415}$

\section{Data collection}

The formal survey was launched on 5 July 2012 and lasted 34 days. It was made up of two parts: face-to-face interview and physical examination. Before the formal survey, we conducted a pre-survey to explore the feasibility of the questionnaire. After the pre-interview, 116 uniformly trained investigators conducted the face-to-face interviews and physical examinations at local health centres or community clinics. All the participants' identities were confirmed by the investigators. During the investigation, each completed questionnaire was examined by two investigators to ensure validity and consistency. After the fieldwork, data were manipulated by parallel double entry, and we also performed three verifications to check for incomplete and inconsistent responses.

The questionnaire provided demographics, lifestyle habits and other related information on health. Height and weight were determined using a standardised protocol with the subjects in light indoor clothing without shoes. Height was measured to the nearest $0.1 \mathrm{~cm}$, and weight to the nearest $0.1 \mathrm{~kg}$.

\section{Definition of variables}

According to the National Bureau of Statistics of China, each selected district or county in this survey was divided into urban and rural areas. ${ }^{16}$ The grading standards for a Chinese adult have been mentioned above: BMI=weight $/$ height $^{2} \quad\left(\mathrm{~kg} / \mathrm{m}^{2}\right) ; \quad 24 \leq \mathrm{BMI}<28$ is overweight; $\mathrm{BMI} \geq 28$ indicates obesity; we used the criterion $\mathrm{BMI} \geq 24$ as the assessment standard of excessive weight. Education was classified into four levels: primary school and below (including those who had never attended school and those with elementary schooling only); junior school; high school (including those with 3 years of secondary vocational schooling); undergraduate and above levels of education. Manual labour included farmers, service workers and production workers. White collar occupations included office and other technical employment. Other occupations included student, unemployed, full-time housewife and retiree. ${ }^{14}$ We defined a smoker as a person who had smoked at least one cigarette a day over the past 30 days. A drinker was defined as a person who had consumed more than one alcoholic drink a week, including any form of alcohol. Participants who were classified as 'eating more meat' were defined as persons who had eaten more animalbased foods than vegetables during meals in the past 30 days. A 'balanced diet' refers to eating animal-based foods and vegetables in equal measure during meals in the past 30 days. Participants who were classified as 'sleep $<7$ h' were defined as persons who slept less than $7 \mathrm{~h}$ over 3 days a week, and those who slept more than $9 \mathrm{~h}$ over 3 days a week were defined as 'sleep $>9 \mathrm{~h}$ '.

\section{Statistical analysis}

We used post-stratification adjustment according to the distribution of regional, urban/rural, age and sex groups in the 2010 census of the adult population of Jilin Province to make the sample estimate of the population of the whole province. Frequency distribution was used to present characteristics of the subjects, and data presented as percentages were used to report the prevalence ratio. Rao-Scott $\chi^{2}$ tests were used to compare the prevalence of overweight and obesity in different groups. To adjust for potential confounding effects, multiple regression analyses were carried out to explore independent factors associated with overweight and obesity. OR with $95 \%$ CI was used for the risk analysis. 
All statistical analyses were conducted using the complex sampling function of SPSS V.20.0, and a $p \leq 0.05$ level of significance was selected. The map was drawn by MapInfo Professional V.7.0 software.

\section{Ethics approval}

This study was approved by the Ethics Committee of Jilin University School of Public Health (reference number 2012-R-011), and written informed consent was obtained from all subjects in the survey.

\section{RESULTS}

In this survey, we interviewed 23050 residents aged over 18 years; 2211 were excluded because of lack of information and other potential bias, leaving 20839 in the final analysis, a response rate of $82.6 \%$ (replacement rate $9.5 \%)$. Of the 20839 subjects, $9873(47.4 \%)$ were men and $10966(52.6 \%)$ were women; ages ranged from 18 to 79 years (mean \pm SD $47.27 \pm 13.34$ ) (table 1 ). According to the BMI classification for Chinese people, the overall prevalence of overweight was $32.3 \%$ (male $34.3 \%$; female; $30.2 \%$ ), and the prevalence of obesity was $14.6 \%$ (male 16.3\%; female 12.8\%) in Jilin Province. Figure 1 shows the geographical position of Jilin Province in northeast China.
From the age-stratified results in table 2, for men, the prevalence of overweight increased with age, peaking at 45-54, while no such trend was seen in the prevalence of obesity. For women, the prevalence of both overweight and obesity increased with age, peaking at 55-64 and $65-79$, respectively. Moreover, the prevalence of overweight was higher in men than women in the age groups $18-54$, and the prevalence of obesity was higher in men than women in the age groups 18-44.

We divided the participants into two groups: normal; overweight and obese. Table 3 shows that the following factors all had a significant effect: sex, age, education, marriage status, occupation, smoking, drinking, diet and sleep quality $(p<0.001)$. We therefore added all these significant factors to a multivariate logistic regression model.

Table 4 shows the results of logistic regression models comparing the prevalence of the potential risk factors: sex, age, level of education, marriage status, occupation, smoking, drinking, diet and hours of sleep. The multivariate logistic regression results reveal that male adults are more likely to become overweight and obese than female adults (OR 1.50, 95\% CI 1.37 to 1.65 ). We categorised age into six groups, which clearly showed that increasing age is a risk factor for overweight/obesity.

Table 1 Prevalence of overweight and obesity according to demographic characteristics

\begin{tabular}{|c|c|c|c|c|c|c|c|}
\hline \multirow[b]{2}{*}{ Characteristic } & \multirow[b]{2}{*}{$\mathbf{n}$} & \multicolumn{3}{|c|}{ Overweight } & \multicolumn{3}{|l|}{ Obesity } \\
\hline & & PR (\%) & $\chi^{2}$ & p Value & PR (\%) & $\chi^{2}$ & p Value \\
\hline \multicolumn{8}{|l|}{ Area } \\
\hline Rural & 10106 & 31.6 & 4.25 & 0.088 & 14.6 & $<0.001$ & 0.996 \\
\hline \multicolumn{8}{|l|}{ Sex } \\
\hline Male & 9873 & 34.3 & 40.58 & $<0.001$ & 16.3 & 50.82 & $<0.001$ \\
\hline $18-24$ & 1128 & 14.5 & \multirow[t]{5}{*}{694.27} & \multirow[t]{5}{*}{$<0.001$} & 7.8 & \multirow[t]{5}{*}{130.16} & \multirow[t]{5}{*}{$<0.001$} \\
\hline 25-34 & 2787 & 27.1 & & & 15.8 & & \\
\hline $35-44$ & 4749 & 34.3 & & & 15.5 & & \\
\hline $45-54$ & 5627 & 39.8 & & & 16.5 & & \\
\hline $55-64$ & 4483 & 40.5 & & & 15.7 & & \\
\hline Senior middle school & 5349 & 33.5 & \multirow{2}{*}{27.81} & \multirow{2}{*}{$<0.001$} & 14.1 & \multirow{2}{*}{7.79} & \multirow{2}{*}{0.171} \\
\hline Undergraduate and above & 3370 & 30.1 & & & 13.6 & & \\
\hline \multicolumn{8}{|l|}{ Marriage } \\
\hline Unmarried & 1569 & 16.7 & \multirow[t]{3}{*}{393.12} & \multirow[t]{3}{*}{$<0.001$} & 10.2 & \multirow[t]{3}{*}{56.95} & \multirow[t]{3}{*}{$<0.001$} \\
\hline Married & 17861 & 34.8 & & & 15.4 & & \\
\hline Separated/divorced/widowed & 1409 & 37.4 & & & 14.1 & & \\
\hline \multicolumn{8}{|l|}{ Occupation } \\
\hline Manual & 11689 & 32.0 & \multirow[t]{3}{*}{3.09} & 0.364 & 14.2 & 33.61 & $<0.001$ \\
\hline White collar & 4078 & 32.1 & & & 12.9 & & \\
\hline Other & 5072 & 33.4 & & & 17.0 & & \\
\hline
\end{tabular}




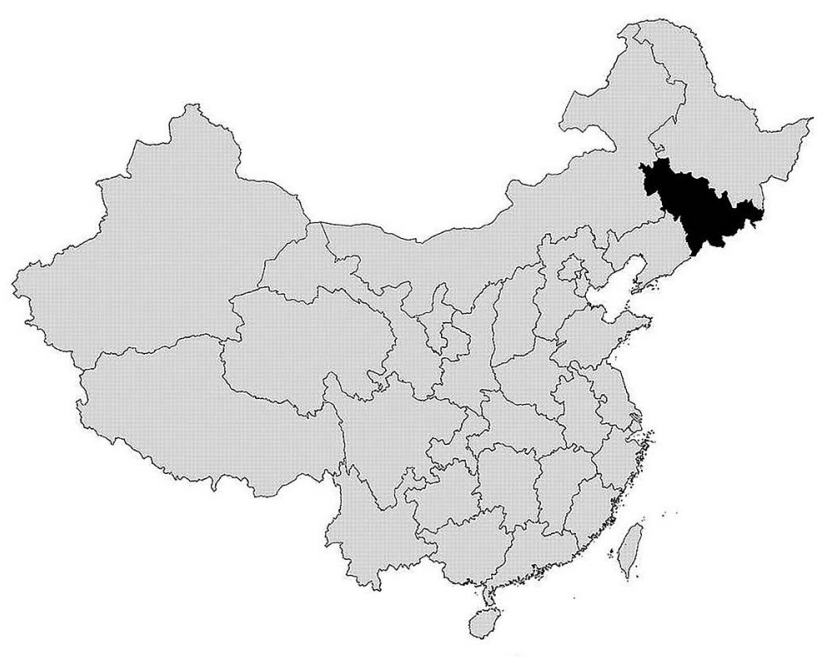

Figure 1 Geographical position of Jilin Province in northeast China.

Participants who have married (OR 1.44, 95\% CI 1.19 to 1.74 ) or are separated/divorced/widowed (OR 1.44, $95 \%$ CI 1.14 to 1.82 ) are more likely to be overweight/ obese than those who have never married. In addition, cigarette smokers (OR $0.70,95 \%$ CI 0.64 to 0.77 ) are less likely to become overweight and obese than nonsmokers and ever-smokers (OR 1.23, 95\% CI 1.07 to 1.40). Participants who drink are more likely to become overweight or obese than those who never or rarely drink (OR 1.11, 95\% CI 1.02 to 1.21). Compared with people on a balanced diet, those who eat more meat (OR $1.47,95 \%$ CI 1.29 to 1.68 ) are more likely to put on weight than those who eat more vegetables (OR 0.83 , $95 \%$ CI 0.77 to 0.89$)$. Overweight and obesity are more common among those who sleep $<7 \mathrm{~h}$ compared with those who sleep $>7 \mathrm{~h}$ (OR $0.89,95 \%$ CI 0.82 to 0.96$)$ and $>9 \mathrm{~h}$ (OR $0.83,95 \%$ CI 0.74 to 0.94 ).

\section{DISCUSSION}

As far as we know, this is the first large population-based face-to-face survey to investigate the prevalence of overweight and obesity in Jilin Province, northeast China. We found that the prevalence of both overweight and obesity was high. From data from the China Chronic
Disease Survey conducted by the Chinese Center for Disease Control and Prevention, the prevalence of overweight among Chinese adults (age 18-64) for 2004, 2007 and 2010 was $23.8 \%, 26.6 \%$ and $30.6 \%$, respectively (male $23.0 \%, 27.4 \%$ and $32.1 \%$; female $24.7 \%, 25.7 \%$ and $29.1 \%$ ), and the prevalence of obesity was $7.2 \%$, $7.7 \% 12.1 \%$, respectively (male $6.3 \%, 6.7 \%$ and $12.5 \%$; female $8.1 \%, 8.7 \%$ and $11.1 \%) .{ }^{17}$ Our cross-sectional study indicates that the prevalence of overweight and obesity among adults in northeast China was $32.3 \%$ (male $34.3 \%$; female $30.2 \%$ ) and $14.6 \%$ (male $16.3 \%$; female $12.8 \%$ ), respectively, in 2012, which is relatively low compared with developed countries. ${ }^{18}$ However, with the rapid economic development of recent years, dietary habits in China have gradually changed from oriental to Western. ${ }^{19}{ }^{20}$ Compared with the prevalence of overweight and obesity at national level, this study shows a higher prevalence in both sexes. This implies that overweight and obesity are more common in northeast China than in other areas, although effective actions might have been taken to control the upward trend. $^{21-23}$

Multivariate logistic regression analysis suggested that several factors are associated with the prevalence of overweight and obesity. The prevalence of overweight is higher in men than women from the age of 18 to 54, and there is a higher prevalence of obesity from the age of 18 to 44, which is in line with previous studies that reported sex difference associated with BMI. ${ }^{24}$ For women, the prevalence of both overweight and obesity increased with age, peaking at 55-64 years. A possible explanation is changes in hormone levels with age. ${ }^{25} 26$

One review from the USA revealed that different marital transitions are associated with changes in body weight for both sexes: transition into marriage appears to be associated with weight gain, whereas transition out of marriage is associated with weight loss. ${ }^{27}$ The present study found the slightly different result that, in adults in northeast China, both transition into marriage and out of marriage are risk factors for becoming overweight and obese. This may be due to racial differences, but the exact mechanism is not clear; further research is needed to illustrate this apparent association with marriage status.

Besides the demographic characteristics mentioned above, behaviours and lifestyle are also found to be

\begin{tabular}{|c|c|c|c|c|c|c|}
\hline \multirow[b]{2}{*}{ Age } & \multicolumn{2}{|c|}{ Overweight } & \multirow[b]{2}{*}{ Female (\%) } & \multicolumn{2}{|l|}{ Obesity } & \multirow[b]{2}{*}{ p Value } \\
\hline & Male (\%) & p Value & & Male (\%) & Female (\%) & \\
\hline $18-24$ & 18.0 & 11.1 & $<0.001$ & 11.4 & 4.2 & $<0.001$ \\
\hline $25-34$ & 31.6 & 21.3 & & 21.1 & 8.9 & \\
\hline $35-44$ & 37.9 & 30.6 & & 18.5 & 12.3 & \\
\hline $45-54$ & 41.0 & 38.5 & & 15.9 & 17.2 & \\
\hline $55-64$ & 39.5 & 41.6 & & 13.8 & 17.6 & \\
\hline $65-79$ & 33.9 & 40.0 & & 9.8 & 17.7 & \\
\hline Total & 34.3 & 30.2 & & 16.3 & 12.8 & \\
\hline
\end{tabular}


Table 3 Univariate analysis of correlates of overweight and obesity in residents of Jilin Province

\begin{tabular}{|c|c|c|c|c|c|c|}
\hline \multirow[b]{2}{*}{ Characteristic } & \multirow[b]{2}{*}{ PR (\%) } & \multirow[b]{2}{*}{ Wald $\chi^{2}$} & \multirow[b]{2}{*}{ p Value } & \multirow[b]{2}{*}{ OR } & \multicolumn{2}{|c|}{$95 \% \mathrm{CI}$ for OR } \\
\hline & & & & & Lower & Upper \\
\hline Area & & 2.39 & 0.122 & & & \\
\hline Urban & 47.5 & & & 1.00 & - & - \\
\hline Rural & 46.2 & & & 0.95 & 0.89 & 1.02 \\
\hline Sex & & 78.15 & $<0.001$ & & & \\
\hline Female & 43.0 & & & 1.00 & - & - \\
\hline Male & 50.6 & & & 1.36 & 1.27 & 1.45 \\
\hline Age & & 77.41 & $<0.001$ & & & \\
\hline $18-24$ & 22.4 & & & 1.00 & - & - \\
\hline $25-34$ & 42.9 & & & 2.60 & 2.16 & 3.14 \\
\hline $35-44$ & 49.8 & & & 3.44 & 2.89 & 4.10 \\
\hline $45-54$ & 56.3 & & & 4.47 & 3.76 & 5.31 \\
\hline $55-64$ & 56.2 & & & 4.46 & 3.74 & 5.32 \\
\hline $65-79$ & 50.9 & & & 3.59 & 2.95 & 4.38 \\
\hline Education & & 8.25 & $<0.001$ & & & \\
\hline Primary school and below & 49.8 & & & 1.00 & - & - \\
\hline Junior middle school & 46.2 & & & 0.86 & 0.79 & 0.94 \\
\hline Senior middle school & 47.6 & & & 0.92 & 0.84 & 1.00 \\
\hline Undergraduate and above & 43.7 & & & 0.78 & 0.70 & 0.87 \\
\hline Marriage & & 101.71 & $<0.001$ & & & \\
\hline Unmarried & 26.9 & & & 1.00 & - & - \\
\hline Married & 50.2 & & & 2.74 & 2.39 & 3.15 \\
\hline Separated/divorced/widowed & 51.2 & & & 2.85 & 2.38 & 3.42 \\
\hline Occupation & & 9.23 & $<0.001$ & & & \\
\hline Manual & 46.2 & & & 1.00 & - & - \\
\hline White collar & 45.0 & & & 0.95 & 0.87 & 1.04 \\
\hline Other & 50.4 & & & 1.18 & 1.08 & 1.29 \\
\hline Smoking & & 53.37 & $<0.001$ & & & \\
\hline No & 46.0 & & & 1.00 & - & - \\
\hline Yes & 45.2 & & & 0.97 & 0.90 & 1.04 \\
\hline Ever & 61.4 & & & 1.86 & 1.65 & 2.11 \\
\hline Drinking & & 32.99 & $<0.001$ & & & \\
\hline Yes & 50.4 & & & 1.00 & - & - \\
\hline No & 45.1 & & & 0.81 & 0.75 & 0.87 \\
\hline Diet & & 24.06 & $<0.001$ & & & \\
\hline Balanced & 46.7 & & & 1.00 & - & - \\
\hline More meat & 56.0 & & & 1.45 & 1.28 & 1.65 \\
\hline More vegetables & 44.4 & & & 0.91 & 0.85 & 0.98 \\
\hline Sleep (hours/night) & & 33.51 & $<0.001$ & & & \\
\hline$<7$ & 51.6 & & & 1.00 & - & - \\
\hline$>7$ & 45.2 & & & 0.77 & 0.72 & 0.83 \\
\hline$>9$ & 41.8 & & & 0.68 & 0.60 & 0.76 \\
\hline
\end{tabular}

$\mathrm{PR}$, prevalence ratio.

associated with body weight. In this study, we found a lower prevalence of overweight and obesity in smokers than non-smokers, which is consistent with studies conducted in India, Switzerland and Tianjin, China. ${ }^{28-30}$ As many studies have reported previously, tobacco use is associated with various chronic diseases and body disorders, which may affect the digestive and absorptive function of the alimentary system. ${ }^{31}{ }^{32}$ Furthermore, some research has also suggested that smoking increases energy expenditure and might suppress appetite. ${ }^{33}$ In addition, it has been suggested that some young people use smoking as a method of weight control; they smoke for the purpose of losing weight. ${ }^{34} 35$ As the use of tobacco does more harm than good, we really do not recommend this way of losing weight.

To the best of our knowledge, diet is one of the most important determinants of body weight. We have observed that drinking and eating more meat are risk factors for being overweight and obese, which is consistent with previous studies. ${ }^{30}$ Animal-based foods contain more fat than other foods, and regular consumption of high-fat foods will lead to weight gain. Affected by the traditional culture of drinking alcohol, especially in northeast China, it is generally believed that, the more you drink, the more emotion you invest in your friends and relatives. Wine is not drunk when people get together. 
Table 4 Multivariate regression analysis of correlates of overweight and obesity in residents of Jilin Province

\begin{tabular}{|c|c|c|c|c|c|c|c|}
\hline \multirow[b]{2}{*}{ Characteristic } & \multirow[b]{2}{*}{ Wald $\chi^{2}$} & \multirow[b]{2}{*}{ p Value } & \multirow[b]{2}{*}{$\boldsymbol{\beta}$} & \multirow[b]{2}{*}{ SE } & \multirow[b]{2}{*}{ OR } & \multicolumn{2}{|c|}{$95 \% \mathrm{Cl}$ for OR } \\
\hline & & & & & & Lower & Upper \\
\hline \multicolumn{8}{|l|}{ Sex } \\
\hline Female & - & - & - & - & 1.00 & - & - \\
\hline Male & 75.04 & $<0.001$ & 0.41 & 0.05 & 1.50 & 1.37 & 1.65 \\
\hline \multicolumn{8}{|l|}{ Age } \\
\hline $18-24$ & - & - & - & - & 1.00 & - & - \\
\hline $25-34$ & 47.71 & $<0.001$ & 0.79 & 0.11 & 2.20 & 1.76 & 2.75 \\
\hline $35-44$ & 79.05 & $<0.001$ & 1.05 & 0.12 & 2.86 & 2.27 & 3.61 \\
\hline $45-54$ & 118.0 & $<0.001$ & 1.30 & 0.12 & 3.65 & 2.89 & 4.61 \\
\hline $55-64$ & 101.00 & $<0.001$ & 1.23 & 0.12 & 3.44 & 2.70 & 4.37 \\
\hline $65-79$ & 49.60 & $<0.001$ & 0.95 & 0.14 & 2.60 & 1.99 & 3.38 \\
\hline \multicolumn{8}{|l|}{ Education } \\
\hline Primary school and below & - & - & - & - & 1.00 & - & - \\
\hline Junior middle school & 2.76 & 0.097 & -0.08 & 0.05 & 0.92 & 0.84 & 1.02 \\
\hline Senior middle school & 1.04 & 0.308 & -0.05 & 0.05 & 0.95 & 0.86 & 1.05 \\
\hline Undergraduate and above & 0.01 & 0.921 & 0.01 & 0.07 & 1.01 & 0.88 & 1.15 \\
\hline \multicolumn{8}{|l|}{ Marriage } \\
\hline Unmarried & - & - & - & - & 1.00 & - & - \\
\hline Married & 13.60 & $<0.001$ & 0.36 & 0.10 & 1.44 & 1.19 & 1.74 \\
\hline Separated/divorced/widowed & 9.50 & 0.002 & 0.37 & 0.12 & 1.44 & 1.14 & 1.82 \\
\hline \multicolumn{8}{|l|}{ Occupation } \\
\hline Manual & - & - & - & - & 1.00 & - & - \\
\hline White collar & 0.59 & 0.443 & -0.04 & 0.06 & 0.96 & 0.86 & 1.07 \\
\hline Other & 26.16 & $<0.001$ & 0.25 & 0.05 & 1.28 & 1.17 & 1.41 \\
\hline \multicolumn{8}{|l|}{ Smoking } \\
\hline No & - & - & - & - & 1.00 & - & - \\
\hline Yes & 56.49 & $<0.001$ & -0.35 & 0.05 & 0.70 & 0.64 & 0.77 \\
\hline Ever & 8.96 & 0.003 & 0.21 & 0.07 & 1.23 & 1.07 & 1.40 \\
\hline Drinking & 5.33 & 0.021 & 0.10 & 0.05 & 1.11 & 1.02 & 1.21 \\
\hline \multicolumn{8}{|l|}{ Diet } \\
\hline Balanced & - & - & - & - & 1.00 & - & - \\
\hline More meat & 33.30 & $<0.001$ & 0.39 & 0.07 & 1.47 & 1.29 & 1.68 \\
\hline More vegetables & 23.53 & $<0.001$ & -0.19 & 0.04 & 0.83 & 0.77 & 0.89 \\
\hline \multicolumn{8}{|l|}{ Sleep (hours/night) } \\
\hline$<7$ & - & - & - & - & 1.00 & - & - \\
\hline$>7$ & 9.67 & 0.002 & -0.12 & 0.04 & 0.89 & 0.82 & 0.96 \\
\hline$>9$ & 8.64 & 0.003 & -0.18 & 0.06 & 0.83 & 0.74 & 0.94 \\
\hline Constant & 83.78 & $<0.001$ & 4.96 & 0.46 & - & - & - \\
\hline
\end{tabular}

Recent studies have shown that poor sleep quality significantly affects BMI. ${ }^{36}$ The results of the present study support this conclusion. A plausible explanation is that sleep disturbances rather than sleep duration may contribute to overweight and obesity, but further studies of the biological mechanisms are needed.

Education level, occupation and area of residence had no significant effect on body weight. Because we used a cross-sectional design in this study, our ability to determine causal inference is limited, and therefore we are unable to explain why these factors are associated or not with overweight and obesity. Further research is needed to better understand why these associations occur, why the observed disparities exist, and how to reverse these trends.

The results of this study form a significant part of the Disease Spectrum in Jilin Province of China, which will be submitted to the Health Department of Jilin Province and other relevant departments as a reference. These departments should heed the high prevalence of overweight and obesity in Jilin Province and provide effective guidelines to help to reverse the trend.

The main strengths of our study are its large sample size and precise physical measurements, which increase the validity of our results. However, some potential limitations exist in this cross-sectional study. Self-reported data and the nature of cross-sectional data may lead to recall and reporting biases, which may have affected the accuracy of the results. The results of this study were from Jilin Province only, and cannot be generalised to the whole of northeast China. In addition, we excluded the item 'exercise', which has always been considered an important factor in overweight and obesity. During the process of data collection, we found 'exercise' was related to the item 'occupation', which may have a large impact on the results. More than $30 \%$ of the participants 
were manual workers, and they claimed that the heavy manual labour they performed left them with no energy to take extra exercise, which resulted in most of the answers to the item about 'exercise' being 'rarely or never'. However, their actual energy consumption should be high. The same was true for full-time housewives because of the housework they performed, especially in rural areas.

\section{CONCLUSIONS}

To sum up, this study suggests that the prevalence of overweight and obesity among adult residents of Jilin Province, northeast China, is high. The main influencing factors for overweight and obesity are sex, age, marriage status, occupation, smoking, drinking, dietary habits and sleep quality.

The results of this study will be submitted to the Health Department of Jilin Province and other relevant departments as a reference, which should inform policy makers in developing education and publicity to prevent and control the occurrence of overweight and obesity.

Acknowledgements The authors would like to thank all participants from the Jilin Province of China and the staff from Jilin University. This study was supported by grants from the Center for Disease Prevention and Control in Jilin Province. In addition, we thank Yang Guo, Department of Epidemiology, Capital Medical University/Beijing Anzhen Hospital, who gave us technical support to complete the revision.

Contributors RW, PZ, CG, XL, YS, ZL, YY and BL designed the study. RW and $P Z$ performed the study. RW analysed the data and drafted the manuscript. RW, PZ, CG, XL and YS participated in amending the manuscript. All authors approved the final version of the manuscript.

Funding This work was supported by a competitive grant from the Scientific Research Foundation of the Health Bureau of Jilin Province, China (2011Z116).

Competing interests None declared.

Patient consent Obtained.

Ethics approval Jilin University School of Public Health.

Provenance and peer review Not commissioned; externally peer reviewed.

Data sharing statement No additional data are available.

Open Access This is an Open Access article distributed in accordance with the terms of the Creative Commons Attribution (CC BY 4.0) license, which permits others to distribute, remix, adapt and build upon this work, for commercial use, provided the original work is properly cited. See: http:// creativecommons.org/licenses/by/4.0/

\section{REFERENCES}

1. Mc Donald A, Bradshaw RA, Fontes F, et al. Prevalence of obesity in panama: some risk factors and associated diseases. BMC Public Health 2015;15:1075.

2. Mehari A, Afreen $\mathrm{S}, \mathrm{Ngwa} \mathrm{J}$, et al. Obesity and pulmonary function in African Americans. PLoS ONE 2015;10:e0140610.

3. Zhang YX, Zhao JS, Chu ZH, et al. Prevalence of elevated blood pressure is associated with the increasing prevalence of obesity among children and adolescents in Shandong, China. Int J Cardiol 2015;201:150-1.

4. Flegal KM, Kit BK, Orpana $\mathrm{H}$, et al. Association of all-cause mortality with overweight and obesity using standard body mass index categories: a systematic review and meta-analysis. JAMA 2013;309:71-82.
5. Wang $\mathrm{H}$, Zhai F. Programme and policy options for preventing obesity in China. Obes Rev 2013;14(Suppl 2):134-40.

6. Addo PN, Nyarko KM, Sackey SO, et al. Prevalence of obesity and overweight and associated factors among financial institution workers in Accra Metropolis, Ghana: a cross sectional study. BMC Res Notes 2015;8:599.

7. Popkin BM, Du S, Zhai F, et al. Cohort Profile: the China Health and Nutrition Survey-monitoring and understanding socio-economic and health change in China, 1989-2011. Int J Epidemiol 2010;39:1435-40.

8. Odum SM, Springer BD, Dennos AC, et al. National obesity trends in total knee arthroplasty. J Arthroplasty 2013;28(Suppl 8): 148-51.

9. Jaacks LM, Gordon-Larsen P, Mayer-Davis EJ, et al. Age, period and cohort effects on adult body mass index and overweight from 1991 to 2009 in China: the China Health and Nutrition Survey. Int $J$ Epidemiol 2013;42:828-37.

10. McGuire S, Shields M, Carroll MD, et al. Adult obesity prevalence in Canada and the United States. NCHS data brief no. 56, Hyattsville, MD: National Center for Health Statistics, 2011. Adv Nutr 2011:2:368-9.

11. He Y, Lam TH, Jiang B, et al. Changes in BMI before and during economic development and subsequent risk of cardiovascular disease and total mortality: a 35-year follow-up study in China. Diabetes Care 2014;37:2540-7.

12. Chen C, Lu FC. The guidelines for prevention and control of overweight and obesity in Chinese adults. Biomed Environ Sci 2004;17(Suppl):1-36.

13. Zhou B, Wu Y, Yang J, et al. Overweight is an independent risk factor for cardiovascular disease in Chinese populations. Obes Rev 2002;3:147-56.

14. Wang $\mathrm{C}, \mathrm{Yu} \mathrm{Y}$, Zhang $\mathrm{X}$, et al. Awareness, treatment, control of diabetes mellitus and the risk factors: survey results from northeast China. PLOS ONE 2014;9:e103594.

15. Wang S, Kou C, Liu Y, et al. Rural-urban differences in the prevalence of chronic disease in northeast China. Asia Pac J Public Health 2015;27:394-406.

16. National Bureau of Statistics of China. China statistical abstract. Beijing, China: China Statistics Press, 2013.

17. Li XY, Jiang $\mathrm{Y}, \mathrm{Hu} \mathrm{N}$, et al. Prevalence and characteristic of overweight and obesity among adults in China, 2010. Chin J Prev Med 2012;46:683-6.

18. Ogden CL, Carroll MD, Curtin LR, et al. Prevalence of overweight and obesity in the United States, 1999-2004. JAMA 2006;295:1549-55.

19. Yin X, Wang L, Li Y, et al. [Red meat intake among employees of floating population aged 18-59 years old in China, 2012]. Zhonghua Liu Xing Bing Xue Za Zh 2014;35:1202-7.

20. Jiang $B Q$, Zhong $P H$, Cheng $X B$, et al. Investigation of health and nutrition status of middle-aged and old residents in the urban district of Chongqing. Asia Pac J Clin Nutr 2007;16(Suppl 1): $17-21$.

21. Qi Xiao ZP, Zhang Y, Wan X, et al. Prevention and control of chronic non-communicable diseases. Chin J Prev Control Chron Noncommun Dis 2012;20:214-15.

22. Notice of the General Office of the State Council on Issuing the outline for the development of China's food and nutrition (2014-2020). In: Council GOotS, ed. Capital Journal of Public Health, 2014:97-9.

23. Notice of the General Office of the Ministry of public health on methods for the management of comprehensive prevention and control of chronic non-communicable diseases. In: Health GOotMop, ed. Ministry of health Bulletin, 2011:28-42.

24. Oliveira GF, Oliveira TR, Ikejiri AT, et al. Prevalence of obesity and overweight in an Indigenous Population in Central Brazil: a population-based cross-sectional study. Obes Facts 2015;8: 302-10.

25. Toth MJ, Tchernof A, Sites CK, et al. Effect of menopausal status on body composition and abdominal fat distribution. Int J Obes Relat Metab Disord 2000;24:226-31.

26. Ruan $X Y$, Gallagher D, Harris $T$, et al. Estimating whole body intermuscular adipose tissue from single cross-sectional magnetic resonance images. J Appl Physiol (1985) 2007;102:748-54.

27. Dinour L, Leung MM, Tripicchio G, et al. The association between marital transitions, body mass index, and weight: a review of the literature. J Obes 2012;2012:294974.

28. Siddiquee T, Bhowmik B, Da Vale Moreira NC, et al. Prevalence of obesity in a rural Asian Indian (Bangladeshi) population and its determinants. BMC Public Health 2015;15:860. 
29. Marques-Vidal P, Bochud M, Mooser V, et al. Prevalence of obesity and abdominal obesity in the Lausanne population. BMC Public Health 2008;8:330.

30. Hu G, Hu G, Pekkarinen $\mathrm{H}$, et al. Comparison of dietary and non-dietary risk factors in overweight and normal-weight Chinese adults. Br J Nutr 2002;88:91-7.

31. Maity P, Biswas K, Roy S, et al. Smoking and the pathogenesis of gastroduodenal ulcer-recent mechanistic update. Mol Cell Biochem 2003;253:329-38.

32. Jayalekshmi PA, Hassani S, Nandakumar A, et al. Gastric cancer risk in relation to tobacco use and alcohol drinking in Kerala, IndiaKarunagappally cohort study. World J Gastroenterol 2015;21:12676-85.
33. Chiolero A, Jacot-Sadowski I, Faeh D, et al. Association of cigarettes smoked daily with obesity in a general adult population. Obesity (Silver Spring) 2007;15:1311-8.

34. Johnson JL, Eaton DK, Pederson LL, et al. Associations of trying to lose weight, weight control behaviors, and current cigarette use among US high school students. J Sch Health 2009;79:355-60.

35. Laz TH, Berenson AB. Association of web-based weight loss information use with weight reduction behaviors in adolescent women. J Adolesc Health 2011;49:446-8.

36. Sun $W$, Huang $Y$, Wang Z, et al. Sleep duration associated with body mass index among Chinese adults. Sleep Med 2015;16:612-16.

37. Sun W, Yuan J, Yu Y, et al. Poor sleep quality associated with obesity in men. Sleep Breath 2015. 